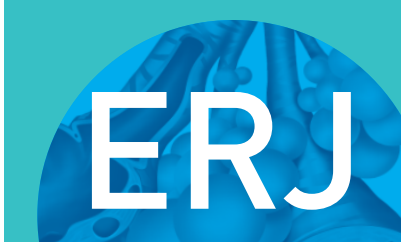

open research

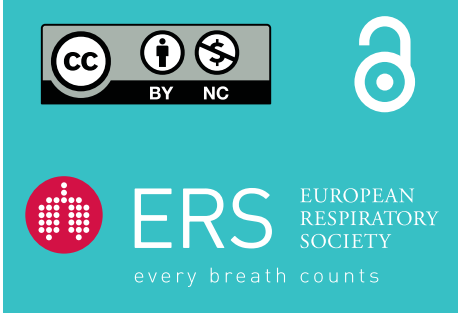

\title{
Minimal important difference of change in patient-specific goals in severe emphysema patients
}

\section{To the Editor:}

Next to clinical response, it is important to include patient-reported outcomes in clinical research to evaluate the treatment effect from a patient's perspective. One example of an important patient-reported outcome is a change in the patient's own specific treatment goals. A questionnaire that can be used to evaluate this outcome is the "patient-specific-complaints (PSC) questionnaire", in which patients can report their three personal most important treatment goals and rate the difficulty to perform this activity on a scale from $0-10$ [1]. This questionnaire provides insight not only in the patient's own goals when undergoing a specific treatment, but also in the change and possible improvements in individual treatment goals over time. Previously, we evaluated this questionnaire in a group of COPD patients who underwent bronchoscopic lung volume reduction treatment with coils and found that the patient's own reported goals significantly improved with a decrease of seven points 1 year after treatment [2]. To our knowledge, there is not yet a minimal important difference (MID) available for this questionnaire. A MID is defined as the smallest change in outcome that is meaningful or important for the patient [3]. This MID could be helpful to interpret whether a statistically significant difference is also clinically relevant for the patient. Therefore, our aim was to establish the MID for change in the patient's own treatment goals after a bronchoscopic lung volume reduction treatment measured by the PSC questionnaire.

Patients who underwent a bronchoscopic lung volume reduction treatment using endobronchial valves or coils in our hospital and who filled out the PSC questionnaire at baseline and follow-up were included in this analysis. We administered this questionnaire in two studies investigating the coil treatment: CROSS-OVER-RENEW (ClinicalTrials.gov identifier: NCT02059057) [2] and REACTION-trial (ClinicalTrials.gov identifier: NCT02179125); and in one study investigating the endobronchial valve treatment: the BREATH-registry (ClinicalTrials.gov identifier: NCT02815683). All studies were reviewed by our medical ethics committee and all patients provided informed consent.

The change in the ability to perform the patient's own specific treatment goals in term of an activity were scored by the PSC. This is a Dutch questionnaire originally developed for lower back pain [1], but also similar to the patient-specific functional scale [4]. Due to its simplicity the questionnaire can be used for all kinds of treatments. Patients report three personal specific treatment goals on the questionnaire and rate using a numeric rating scale from 0-10 how difficult it was to perform the activity. A score of "0" indicates no difficulty at all to perform the activity, whereas a score of "10" indicates it is impossible to perform. The outcome for the MID analysis was the sum score of the three activities (range 0-30, see questionnaire example in figure 1a). Patients scored the questionnaire before treatment and 3 months (REACTION-study) or 12 months (CROSS-OVER-RENEW and BREATH studies) after treatment. Furthermore, patients performed body plethysmography and spirometry according to the European Respiratory Society/American Thoracic Society (ATS) guidelines [5, 6], a 6-min walking distance(6MWD) test according to the ATS guidelines [7] and filled out the St George's respiratory questionnaire (SGRQ) [8] before and after treatment.

@ERSpublications

Change in patient's personal treatment goals is an important patient-reported outcome and can be measured by the patient-specific complaints (PSC) questionnaire. This paper establishes the MID for this questionnaire as $\mathbf{- 5 . 9}$ points. https://bit.ly/3kwvWKM

Cite this article as: Hartman JE, Klooster K, Koster TD, et al. Minimal important difference of change in patient-specific goals in severe emphysema patients. ERJ Open Res 2020; 6: 00459-2020 [https://doi.org/10.1183/23120541.00459-2020]. 
a)

Instruction

Please report the 3 for you most important activities that you hope will change after treatment. Furthermore, indicate on the scale below per activity, how difficult it was to perform this activity in the past week.

Activity 1:_Walking

How difficult was it to perform this activity in the past week?

$\begin{array}{llllllllllllll}\text { Easy to perform } & 0 & 1 & 2 & 3 & 4 & 5 & 6 & 7 & 8 & 9 & 10 & \text { impossible to perform }\end{array}$

Activity 2:-Household chores

How difficult was it to perform this activity in the past week?

$\begin{array}{lllllllllllll}\text { Easy to perform } & 0 & 1 & 2 & 3 & 4 & 5 & 6 & 7 & 8 & 9 & 10 & \text { impossible to perform }\end{array}$

Activity 3:_shopping

How difficult was it to perform this activity in the past week?

$\begin{array}{llllllllllllll}\text { Easy to perform } & 0 & 1 & 2 & 3 & 4 & 5 & 6 & 7 & 8 & 9 & 10 & \text { impossible to perform }\end{array}$

SUMSCORE: Total of the 3 activities, range $0-30$

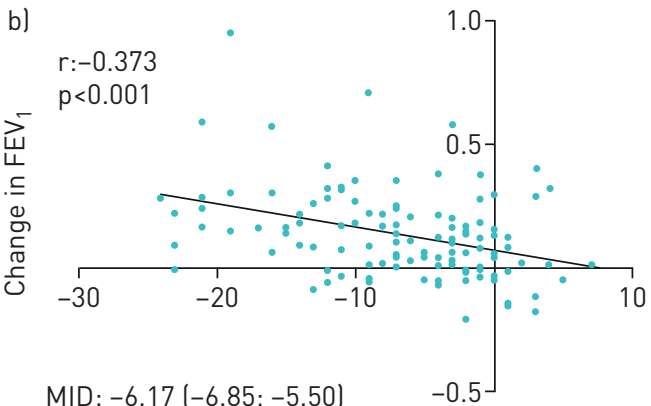

Change in PSC

d

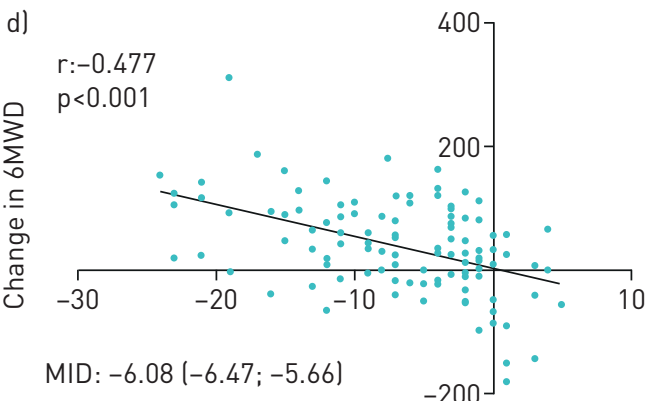

Change in PSC

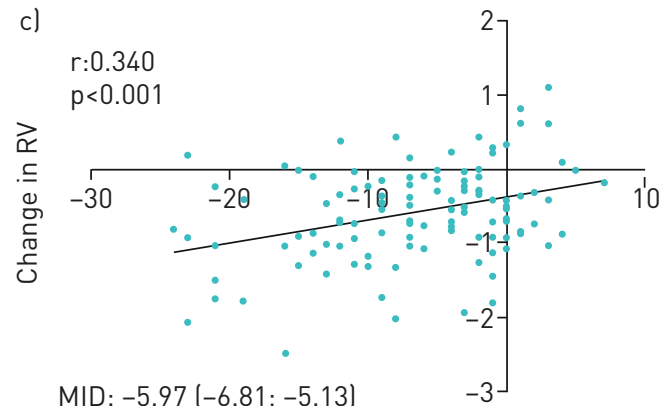

Change in PSC

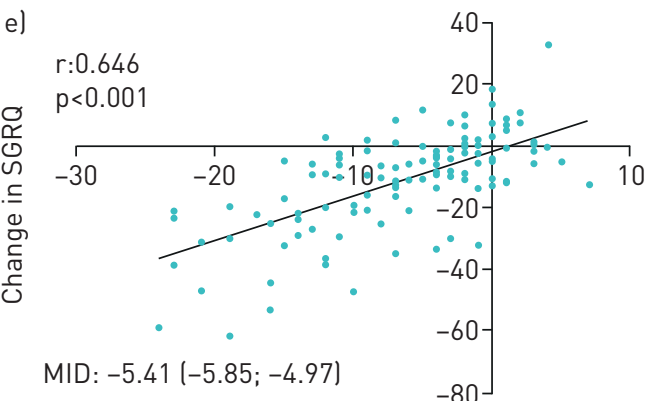

Change in PSC

FIGURE 1 a) Example of the patient-specific complaints questionnaire (PSC). b-e) Scatterplots of change in PSC with change in anchors and estimated minimal important difference (MID) (95\% CI) per anchor. b) Association between change in PSC and change in forced expiratory volume in $1 \mathrm{~s}\left(\mathrm{FEV}_{1}\right)$. c) Association between change in PSC and change in residual volume (RV). d) Association between change in PSC and change in 6-min walking distance (6MWD). e) Association between change in PSC and change in St George's Respiratory Questionnaire (SGRQ). r=Pearson correlation coefficient. 
We used the anchor-based method to calculate the MID. This method compares the change in the outcome measure with an earlier established MID of another clinical outcome ("the anchor"). The anchors chosen for this analysis were: residual volume (RV) $\left(430 \mathrm{~mL}\right.$ [9]), forced expiratory volume in $1 \mathrm{~s}\left(\mathrm{FEV}_{1}\right)$ (100 mL [10]), 6MWD (26 m [11]) and SGRQ total score (7.1 points [12]). First, we calculated the Pearson correlation coefficient between the change in PSC questionnaire and the change in the various anchors, as there needs to be an appropriate association for an anchor to be used. We accepted a statistically significant $(\mathrm{p}<0.05)$ correlation coefficient of $\geqslant 0.3$ in line with reference [13]. In cases where the anchor had an appropriate association, we performed a linear regression analysis with the change in PSC as dependent variable and the change in anchor as the independent variable. To calculate the MID per anchor we entered the MID of the anchor in the regression equation. The final MID was the average of all the MIDs calculated by the different anchors. All statistical analyses were performed using IBM SPSS Statistics version 23 (IBM Corp., Armonk, NY, USA).

In total 123 patients filled out the PSC questionnaire at baseline and follow-up and were included (28\% male, mean age 62 years, $\mathrm{FEV}_{1} 28 \%$ of predicted, RV 237\% of predicted, 6MWD $326 \mathrm{~m}$ ). 35 patients (28\%) underwent the coil treatment (CROSS-OVER-RENEW and REACTION-trial) and 88 patients $(72 \%)$ underwent the endobronchial valve treatment (BREATH-registry). The PSC-sum score significantly improved after treatment from 23.5 to 17.0 (mean change 6.5, $\mathrm{p}<0.001$ ).

In figure $1 \mathrm{~b}-\mathrm{e}$ scatterplots are shown of the association between the change in PSC-sum score and the four different anchor variables, including the Pearson correlation coefficient and established MIDs. All anchors were significantly associated with a correlation coefficient above 0.3 . The MID estimates derived from the linear regression equation were $\mathrm{FEV}_{1}$ : -6.17 , RV: -5.97 , SGRQ: -5.41 and 6MWD: -6.08 , leading to an mean MID of -5.91 .

So to summarise, we established the MID for measuring change in a patient's own reported treatment goals by using the PSC questionnaire sum score, with an MID of -5.91 points.

The questionnaire we used is not a well-known questionnaire. However, the concept of the questionnaire is really simple, which is probably why two similar questionnaires already exist [1,4]. Practically, the questionnaire consists of three self-reported goals in terms of an activity and the scoring of the difficulty of these activities on a numeric rating scale of $0-10$. In our opinion, the questionnaire can be applied to evaluate various treatments. Furthermore, we believe that a patient's personal treatment goals and whether these actually improve after treatment are clinically relevant outcomes. Patient-reported outcomes should be included more in clinical research and this questionnaire could be one of them.

Although the questionnaire is applicable for different treatments and patient populations, we believe our established MID is not. For example, TroosTers [14] showed that different interventions can have different effects on the relationship between the "anchor" and the dependent outcome, in this example the SGRQ total score. This can be caused by the effect size of different treatments and subsequently the results patients expect of the treatment. Therefore, we suppose this MID is primarily calculated for patients who undergo a bronchoscopic lung volume reduction treatment and further research will be needed to show whether this MID is generalisable to other treatments or not.

The REACTION-trial had a shorter follow-up compared to the other trials, 3 months versus 12 months. This could have influenced the results since an MID could be different for the short term versus the longer term, as has been demonstrated for the MID for the SGRQ established by WeLLING et al. [12] in patients with severe COPD undergoing bronchoscopic lung volume reduction. However, when we performed the analysis without patients from the REACTION-trial there was no difference in the established MID. We therefore decided to include all patients.

In conclusion, we established the MID for the evaluation of patient-specific treatment goals in COPD patients after a bronchoscopic lung volume reduction treatment measured by the PSC questionnaire for the first time. The established MID is -5.9 points and this could be useful for evaluating the meaningfulness of reported changes using this questionnaire and potentially for power calculation for future efficacy studies in this patient group.

Jorine E. Hartman $\odot$, Karin Klooster, T. David Koster, Marlies van Dijk ๑ and Dirk-Jan Slebos $\odot$ Dept of Pulmonary Diseases and Groningen Research Institute for Asthma and COPD, University of Groningen, University Medical Center Groningen, Groningen, The Netherlands.

Correspondence: Jorine E. Hartman, Dept of Pulmonary diseases AA11, University Medical Center Groningen, PO Box 30001, 9700 RB Groningen, The Netherlands. E-mail: j.hartman@umcg.nl 
Received: 2 July 2020 | Accepted: 3 Aug 2020

Conflict of interest: J.E. Hartman has nothing to disclose. K. Klooster reports a speaker's fee and travel reimbursement from PulmonX outside the submitted work. T.D. Koster has nothing to disclose. M. van Dijk has nothing to disclose. D-J. Slebos reports grants and nonfinancial support from, and work as a principal investigator and investigator from PulmonX, CA, USA, and PneumRx/BTG, outside the submitted work.

\section{References}

1 Beurskens AJ, De Vet HC, Koke AJ, et al. A patient-specific approach for measuring functional status in low back pain. J Manipulative Physiol Ther 1999; 22: 144-148.

2 Hartman JE, Klooster K, ten Hacken NHT, et al. Patient-specific goals significantly improve after endobronchial coil treatment in patients with severe emphysema. Clin Respir J 2018; 12: 2157-2158.

3 Copay AG, Subach BR, Glassman SD, et al. Understanding the minimum clinically important difference: a review of concepts and methods. Spine J 2007; 7: 541-546.

4 Stratford P, Westaway GM, Binkley J. Assessing disability and change on individual patients: a report of a patient specific measure. Physiother Canada 1995; 47: 258-263.

5 Wanger J, Clausen JL, Coates A, et al. Standardisation of the measurement of lung volumes. Eur Respir J 2005; 26: $511-522$.

6 Miller MR, Hankinson J, Brusasco V, et al. Standardisation of spirometry. Eur Respir J 2005; 26: 319-338.

7 ATS Committee on Proficiency Standards for Clinical Pulmonary Function Laboratories. ATS statement guidelines for the six-minute walk test. Am J Respir Crit Care Med 2002; 166: 111-117.

8 Jones PW, Quirk FH, Baveystock CM. The St George's Respiratory Questionnaire. Respir Med 1991; 85 Suppl B 25-31; discussion 33-7.

9 Hartman JE, Ten Hacken NHT, Klooster K, et al. The minimal important difference for residual volume in patients with severe emphysema. Eur Respir J 2012; 40: 1137-1141.

10 Donohue JF. Minimal clinically important differences in COPD lung function. COPD J Chronic Obstr Pulm Dis 2005; 2: 111-124.

11 Holland AE, Hill CJ, Rasekaba T, et al. Updating the minimal important difference for six-minute walk distance in patients with chronic obstructive pulmonary disease. Arch Phys Med Rehabil 2010; 91: 221-225.

12 Welling JBA, Hartman JE, Ten Hacken NHT, et al. The minimal important difference for the St George's Respiratory Questionnaire in patients with severe COPD. Eur Respir J 2015; 46: 1598-1604.

13 Revicki D, Hays RD, Cella D, et al. Recommended methods for determining responsiveness and minimally important differences for patient-reported outcomes. J Clin Epidemiol 2008; 61: 102-109.

14 Troosters T. How important is a minimal difference? Eur Respir J 2011; 37: 766-756. 